\title{
Using AVAL-1D to simulate avalanches in eastern Pyrenees
}

\author{
Pere Oller ${ }^{1, *}$, Marc Janeras ${ }^{2}$, Hèctor de Buen ${ }^{2}$, Georgina Arnó ${ }^{2}$, Marc Christen $^{3}$, Carles García $^{1}$, Pere \\ Martínez ${ }^{1}$ \\ ${ }^{1}$ Institut Geològic de Catalunya \\ ${ }^{2}$ Geocat Gestió de Projectes \\ ${ }^{3}$ WSL Institute for Snow and Avalanche Research SLF
}

\begin{abstract}
The numerical avalanche dynamics program AVAL-1D, developed by the WSL Institute for Snow and Avalanche Research SLF, was calibrated empirically with real avalanches in the Swiss Alps. For the simulation of avalanches with this program, the SLF recommends the use of two friction parameters obtained for this purpose. Applying these parameters to other regions with different characteristics can lead to inaccuracies if a previous calibration is not performed, but often there is not enough data to do a proper calibration when an avalanche is simulated in a specific avalanche path. For this reason, an investigation to determine the specific parameters to be used in the Catalan Pyrenees was performed. This study was based on back-calculations of well documented events. Twelve dense flow or mixed avalanche events, from small to large size, were selected from nearly 2500 avalanches stored in the Avalanche Database of Catalonia (BDAC). The availability of morphometric and dynamics data, necessary for this purpose, was the critical factor to reject several cases. The result of the study reveals that there is a good fit between the recorded avalanche events and the simulated one's using the SLF recommended parameters.
\end{abstract}

KEYWORDS: hazard mapping, AVAL-1D, Pyrenees, friction parameters.

\section{INTRODUCTION}

In 2004 an avalanche hazard mapping plan for the Catalan Pyrenees, was started. The first phase of the plan consisted on the development of the necessary knowledge bases for its further development. One main line of work was the validation and calibration of the chosen model for the numerical simulation of avalanches, as a complement of the information obtained from terrain analysis and from the avalanche inventory. It was decided that AVAL-1D would be the program recommended by the IGC for such work. The main argument for choosing this program was its widespread and proven use at international level (Jamieson et al., 2008), and that since 2000, the IGC has been using it in its avalanche hazard reports.

On the south side of the Pyrenees, there are not many works related to avalanche modeling. The first pioneering work was done by Furdada (1996) with the implementation of the Norwegian statistical model, or $\alpha-\beta$ (Bakkehoi and Lied, 1980) obtaining an algorithm applied to the regional specificities of the Pyrenees. Lopez et al. (1997), applied for the first time, the Swiss program Lawsim, based on the dynamic model

Corresponding author address: Pere Oller, Institut Geològic de Catalunya, C/Balmes 209, 08006, Barcelona;

tel: +34 935538430; fax: +34 935538436;

email: pereo@igc.cat of Voellmy-Salm (Salm et al., 1990), the predecessor of AVAL-1D, for the designing of protection works on the southern entrance of the Somport tunnel (Canfranc, Aragonese Pyrenees). Janeras and Furdada (2002) presented the first results of the use of AVAL-1D in the Andorran Pyrenees for determining the risk generated by the avalanche of the "Armiana de Canillo". More recently, García et al. (2006), applied the statistical $\alpha-\beta$ and the dynamic Voellmy-Salm models to the "torrente Epifanio" avalanche for the hazard assessment in Canfranc International Station (Aragonese Pyrenees).

According to Jamieson et al. (2008), there are two basic ways to implement dynamic models in hazard mapping: the direct and the indirect calibration. In the direct calibration, for the path to be mapped, the friction parameters are adjusted so that the dynamic model stops at an extreme runout determined from the avalanche inventory. Sometimes it is called backcalculation of friction coefficients. Indirect calibration uses resistance and flow parameters taken from extreme runouts in other paths and/or published values to estimate extreme runouts in the path to be mapped.

Hence, the main objective of the study was the direct calibration from well-known observed avalanches, for using the model in the future with greater accuracy, and when appropriate, to have reliable data for the indirect calibration. 


\section{STUDY AREA}

The study area corresponds to Catalan Pyrenees, the southeastern part of the Pyrenean range (Figure 1). This part of the Pyrenees is $146 \mathrm{~km}$ long by $52 \mathrm{~km}$ at its widest part (west) and $19 \mathrm{~km}$ in the narrowest (East), constituting an area of $5214 \mathrm{~km}^{2}$. The highest peaks exceed $3000 \mathrm{~m}$ a.s.l., but roughly they range between 2500 and $3000 \mathrm{~m}$ a.s.l.. The timberline ranges between 2100 and $2300 \mathrm{~m}$ a.s.l.. Three different climate varieties were identified (Garcia et al., 2007). The northwestern part has a humid oceanic climate. Precipitation is abundant and the annual amounts do not vary significantly from year to year. Towards the south, the climate gradually becomes more continental and rainfall decreases. Precipitation in winter is reduced, becoming a dryer season, and increases in the equinoctial seasons. In the easternmost part, the oceanic influence disappears and the Mediterranean influence takes a significant role. Winter is particularly dry, with sometimes intense though less frequent precipitation.

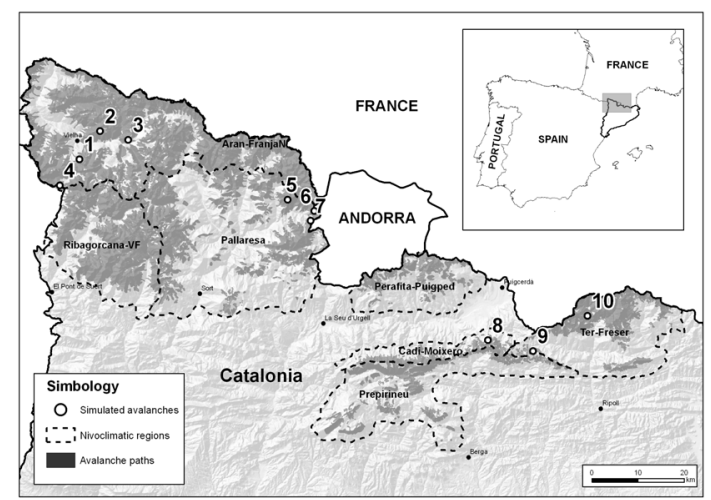

Figure 1. Map showing the location of the studied avalanches, and the avalanche forecasting regions established for the Catalan Pyrenees. "Aran-Franja nord de la Pallaresa": oceanic climate; "Ribagorçana", "Pallaresa", "PerafitaPuigpedrós", "Vessant nord del Cadí-Moixeró": continental influence climate. "Prepirineu" and "Ter Freser": Mediterranean influence climate.

\section{MATERIAL AND METHODS}

\subsection{AVAL-1D}

AVAL-1D (Christen et al., 2002) allows the simulation of avalanches in one dimension from the starting zone to the runout. It predicts runout distances, flow velocities and impact pressures of both flowing and powder snow avalanches at every point of a specified avalanche track. It consists of two modules: FL-1D, for dense flow avalanches, and SL-1D, for powder snow avalanches. These modules solve the conservation of mass and momentum equations, using an upwinded finite difference scheme.

In this paper we show the results obtained with the calibration of the FL-1D model. For this purpose a set of inputs is needed: topographic profile of the avalanche, avalanche width and morphology of the terrain along the path, area of the starting zone and release snow depth, and friction parameters ( $\mu$ and $\xi$ ). The SLF recommends the use of friction values, obtained experimentally in the Alps, detailed in a table. These values vary in relation with the release volume, the elevation, the morphology of the terrain, the type of flow and the return period. The application of the model in other mountain ranges requires a previous validation (Christen et al., 2002). Examples of the validation are the works done by Casteller et al. (2008) in Patagonia, Argentina, and Mears (2006) in Colorado (United States).

\subsection{Selection of the avalanches to simulate}

For the direct calibration of the model we worked with records of avalanches observed and stored in the BDAC (Oller et al., 2006). At present 2441 avalanches have been recorded since 1986-87 season. Nevertheless, it is difficult to find records containing all the dynamic and morphometric data to be used in the calibration of the model. Moreover, the limited time space (22 years) indicates a low probability of having extreme records. So, the selection of avalanches was very limited. For its selection, it was determined that they had to be avalanches with a return period of, at least, 30 years. 12 avalanches were identified.

Some characteristics of these avalanches are shown in figures 2 and 3 . They represent the three climate varieties (Figure 1), and a return period of approximately 30 years was estimated for them.

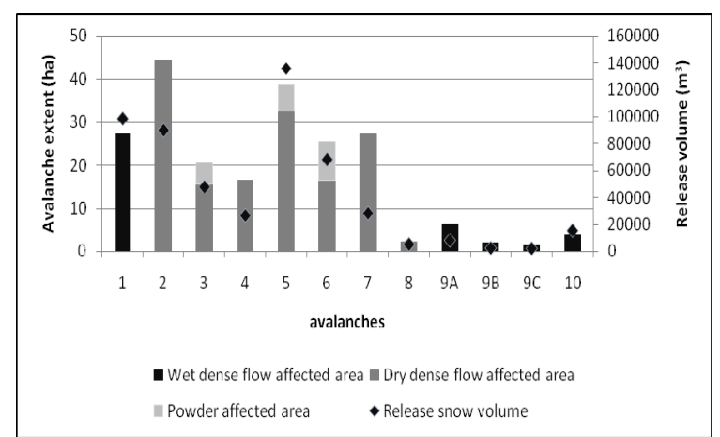

Figure 2. Extension affected by the different phases of the flow and calculated release volume, for the 12 selected avalanches. 


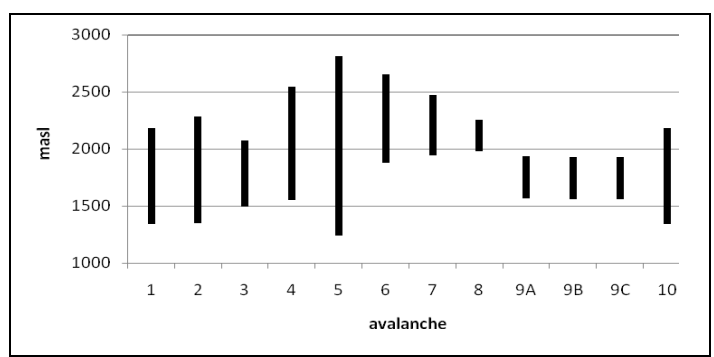

Figure 3. Starting zone and runout elevations of the 12 studied avalanches.

The following information was available for the study:

- Avalanche cartography in digital form: envelope of the avalanche, distinguishing the area affected by the dense part and the area affected by the powder part.

- Descriptive form of the avalanche, including date of occurrence, triggering conditions, morphometric and dynamic data, and damage caused.

- Graphic information: pictures of the avalanche taken during the field mapping.

- Nivometeorological information previous to the triggering of the avalanche: daily data and snow profiles of different monitoring stations near the area where the avalanche occurred.

\subsection{Determining the inputs}

To provide maximum accuracy a data revision and updating process was done, consisting of:

(1) Improving the accuracy of the cartographies using the graphic information available (photographs of the triggered avalanche and ortophotos).

(2) Generation of the representative topographic profile for each path, considering the possible trajectories, flow widths and, in case of flow division, considering the mass loss in the final outcome.

(3) Estimation of the release snow depth. This is one of the critical parameters for the calibration of the model. The problem lies in the reliability of the data. The previous values were obtained through observation at a distance. This represents a remarkable degree of inaccuracy due to the absence of reliable references for measurement. Moreover, the value usually does not correspond to the average value but the value of maximum depth. For this reason we proceeded to analyze the data and snow profiles from each path. We extracted the average thickness of snow potentially mobilized, which probably improves the previous estimation. Two cases were differentiated. (a) Full depth wet snow avalanches: it was considered that the released vertical thickness was equal to the snowpack thickness. (b) Recent snow avalanches: the procedure proposed by Salm et al. (1990) was followed. This data came from stations near the site of the released avalanche triggering.

(4) Estimation of the area of departure. The main challenge was to determine the bottom boundary ("stauchwall") of the starting zone. We followed three criteria. (a) Hard slabs: the starting zone was determined by measuring this parameter where the crown of the slab disappears laterally. (b) Soft slabs: the bottom line was located where the width of the slab starts to narrow laterally. (c) Full depth slab: in this case, where all of the terrain was visible, was considered as the starting area.

Parameters related to geometry and topography of the avalanche requires a good mapping of the event, specially the estimation of the flow width. But the determination of the initial conditions (snow depth and release area) is the step that can introduce major error in the modeling because they were based on assumptions.

(5) Selection of $\mu$ and $\xi$ parameters. First, the SLF recommended values were chosen. If no adjustment was attained, they would be modified to obtain the best fit, and to analyze their influence in the results.

\subsection{Calibrating the dense flow model FL-1D}

The calibration of the flow model for dense avalanches, FL-1D, for the 12 avalanches followed the next steps:

(1) Selection of input parameters specified in section 3.3.

(2) Control simulation: once the initial parameters had been selected, a first test was done by running the model. The goal was to have a preliminary overview of the critical points of modeling and to detect potential instabilities in the calculation process, which would be eliminated in future iterations.

(3) Calculation iterations: this stage was an iterative process of introduction of small changes, mostly in release conditions and on the friction parameters inside the edges of uncertainty of observational data, to achieve the best fit between the modeling results and real observations.

(4) Selection of the simulation that presents the best fit and rating of the results: once we got a good approximation between modeling and real observations, it was checked that either, the initial parameters entered into the model and the results in terms of speed, flow height and pressure, were consistent. 


\section{RESULTS AND DISCUSSION}

The accuracy of the results was evaluated from the fit obtained in the runout distance of the avalanche. In the absence of speed and flow height data, these parameters were not used for calibration.

The end point of the calculated runout distance was established where pressure values fall below $0.3 \mathrm{kPa}$. The model generally simulates, in the distal part of the deposit, a remaining flow of low thickness and low speed due to numerical diffusion. This fact makes it difficult to determine the runout distance considering the flow height and it can lead to erroneous results. Hence, this pressure criterion, used by the SLF as the end of blue-white hazard zones in hazard mapping, was used. In some simulations, due to the numerical diffusion, areas with increased pressure form ahead of the found end point. (figure 4). These zones were not considered.

Regarding this criterion, simulated runout distance values where obtained for each ava- lanche profile. The calculated values, compared with the observed ones, are shown in table 1.

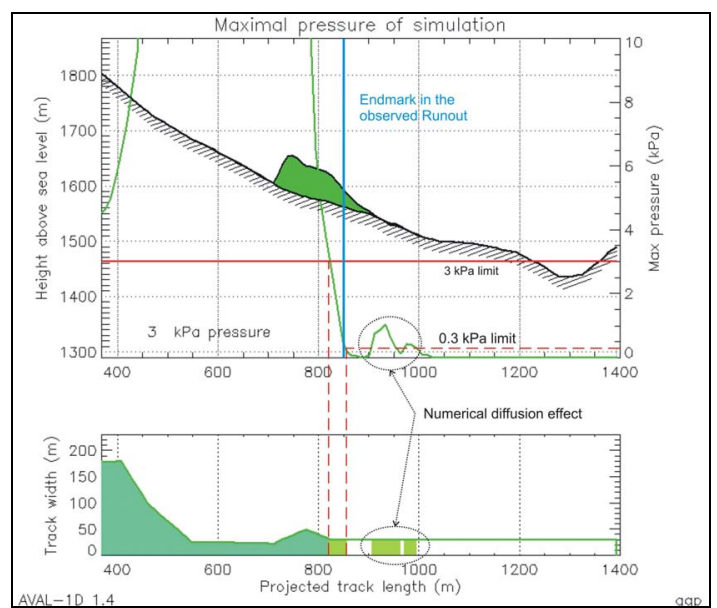

Figure 4. Pressure plot of the simulated runout deposit of avalanche $9 a$ and determination of the end point.

\begin{tabular}{|c|c|c|c|c|}
\hline Avalanche & $\begin{array}{l}\text { Observed length }\left(X_{0}\right) \\
(m)\end{array}$ & $\begin{array}{l}\text { Simulated length }\left(X_{s}\right) \\
(m)\end{array}$ & $\begin{array}{c}\text { Difference } X_{0}-X_{s}(P=0.3 \mathrm{kPa}) \\
(\mathrm{m})\end{array}$ & $\begin{array}{c}\text { Relative values }(\mathrm{P}=0.3 \mathrm{kPa}) \\
(\%)\end{array}$ \\
\hline 1 & 1930 & 1888 & -42 & -2.18 \\
\hline 2 & 2020 & 1984 & -36 & -1.78 \\
\hline 3 & 1302 & 1302 & 0 & 0.00 \\
\hline 4 & 1749 & 1759 & 10 & 0.57 \\
\hline 5 & 3366 & 3333 & -33 & -0.98 \\
\hline 6 & 1933 & 1960 & 27 & 1.40 \\
\hline 7 & 1181 & 1149 & -32 & -2.71 \\
\hline 8 & 491 & 491 & -5 & -1.02 \\
\hline $9 a$ & 651 & 681 & 30 & 4.61 \\
\hline $9 b$ & 579 & 599 & -18 & -3.11 \\
\hline $9 c$ & 591 & 542 & 24 & 4.06 \\
\hline 10 & 852 & 842 & -16 & -1.88 \\
\hline \multicolumn{2}{|r|}{ Mean } & 1377.5 & -7.6 & -0.3 \\
\hline \multicolumn{2}{|c|}{ Absolute values mean } & 1377.5 & 22.8 & 2.0 \\
\hline \multicolumn{2}{|c|}{ Standard deviation } & 845.14 & 25.92 & 2.52 \\
\hline
\end{tabular}

Table 1. Runout distance values obtained for each avalanche profile and differences with the observed ones.

The results show an average adjustment of $2.0 \%$ considering all the avalanche length from the starting to the end point, which represents an average error, in absolute values, of $23 \mathrm{~m}$, with a light tendency to underestimate the runout distance. The maximum error was obtained in avalanche 1 , with $-42 \mathrm{~m}$, while in three cases (avalanches 3, 4 and 8) the adjustment was for less than $10 \mathrm{~m}$.

The results are quite satisfactory. We consider that they are within the accuracy range that the input parameters allow. Once they were fixed, trying to improve the results by changing recommended friction values we obtained less realistic results. On the other hand, non significant trends were observed due to Pyrenean regional particularities.

\section{CONCLUSIONS}

With the dense flow model from AVAL-1D, FL-1D, we obtained satisfactory results in terms of runout distance of the avalanches with a return period of 30 years, using the SLF recommended values, and considering the end point at a pressure limit of $0.3 \mathrm{kPa}$. Possible trends due to Pyrenean regional conditions, the purpose of this study, were not found. 
This study has the aim to give some advice for Pyrenean AVAL-1D users. But it must be taken into account that the results are for reference only. For this reason, when modeling, if there is appropriate information, a direct calibration should be done.

This work also served to identify gaps in the data recording to the BDAC. We must make an effort to obtain reliable data from observed avalanches. These shortcomings must be improved so that available data could be useful in future studies.

\section{ACKNOWLEDGEMENTS}

The authors wish to acknowledge the support received by Stefan Margreth and Lukas Stoffel from the SLF.

\section{REFERENCES}

Casteller, A.; Christen, M.; Villalba, R.; Martínez, H.; Stöckli, V.; Leiva, J.C., Bartelt, P. (2008). Validating numerical simulations using dendrochronology: the Cerro Ventana event in Northern Patagonia, Argentina. Nat. Hazards Earth Syst. Sci., 8, 433-443.

Christen, M.; Bartelt, P.; Gruber, U. (2002). AVAL-1D: an avalanche dynamics program for the practice. Interpraevent 2002. Matsumoto - Japan. Congress publication, vol. 2, pp. 715-725.

Furdada, G. (1996): Estudi de les allaus al Pirineu Occidental de Catalunya: predicció espacial i aplicacions a la cartografia. Geoforma ediciones, Logroño. 315 pp.

García, C.; Martí, G.; García, A.; Muntán, E.; Oller, P.; Esteban, P. (2007): Weather and snowpack conditions of major avalanches in the Catalan Pyrenees. Proceedings of the Alpine Snow Workshop. Forschungsbericht 53. P. 49-56.

García, JL; Cuchí, JA; Fábregas, S; Arrazola, JF (2006). La protección de poblaciones e infraestructuras contra aludes. El caso del torrente Epifanio en Canfranc (Huesca). Actas del III Congreso de Ingeniería Civil, Territorio y Medio Ambiente. Zaragoza, 25-27 de octubre de 2006.

Jamieson, B.; Margreth, S.; Jones, A. (2008). Application and limitations of dynamic models for snow avalanche hazard mapping. Proceedings of the ISSW 2008. Wistler, Canada. P. 730-739.

Janeras, M. \& Furdada, G. (2002). Gestión del riesgo de aludes: metodología de análisis y planificación territorial y aplicación a L'Armiana de Canillo (Andorra). En Estudios recientes (2000-2002) en Geomorfología. Patrimonio, montaña y dinámica territorial. VII Reunión Nacional de Geomorfología (SEG), Valladolid. pp. 99-108.

Lied, K.; Bakkehoi, S. (1980). Empirical calculations of snow-avalanche run-out distance based on topographic parameters. Journal of Glaciology, Vol.26, No. 94, 1980.
Lopez, R.; Sarasa, A.; Oller, P. (1997):

Caracterización, simulación y prevención de aludes en el Barranco de Secras, Tunel de Somport (Huesca). IV Simposio nacional sobre taludes y laderas inestables. P. 703-717. Granada.

Mears, A.I. (2006). Avalanche size increase resulting from forest removal and wind loading - a case study from Central Colorado using AVAL-1D. Proceedings of the ISSW 2008. Wistler, Canada. P. 775-777.

Oller, P.; Muntán, E.; Marturià, J.; García, C.; García, A.; Martínez, P. (2006): The avalanche data in the Catalan Pyrenees. 20 years of avalanche mapping. Proceedings of the International Snow Science Workshop. Telluride, Colorado (USA). P. 305-313. October 1-6, 2006.

Salm, A.; Burkard, A.; Gubler, H.U. (1990).

Berechnung von fliesslawinen eine anleitung für praktiker mit beispielen. Eigdenöischen Institut für Schnee und Lawinenforschung. Nr. 47. 